\title{
CAPACITAÇÃO SOBRE \\ PROCESSO COLABORATIVO \\ PARA EMPRESAS JUNIORES
}

Modalidade : Experiência de ensino-aprendizagem BIM realizadas.

\section{DESENVOLVIMENTO}

A capacitação teve participação de 40 pessoas e carga horária total de 10 horas, nas quais trabalharam-se as etapas de criação de projetos de construção civil - na fase estrutural, arquitetônica e de instalação elétrica por intermédio de uma abordagem teórico-prática dos principais aspectos sobre compatibilização, utilização das ferramentas BCF, BIMcollab e Naviswork. A iniciativa teve como competência abordada a técnica e a operação, de acordo com a elucidação exposta por Succar, Sher e Williams (2013).

Figura 1: Resultado, obtido por meio de questionário, sobre os conhecimentos prévios dos participantes.

Você tinha algum conhecimento prévio sobre os conteúdos abordados?

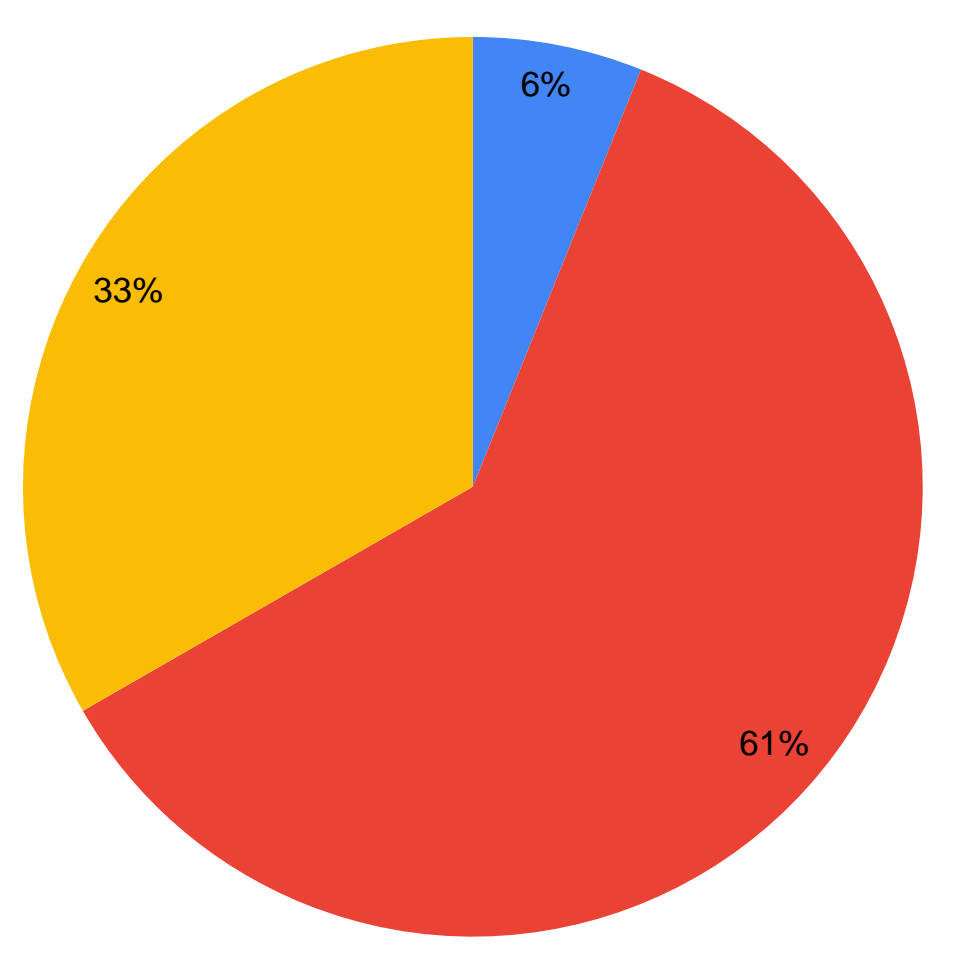

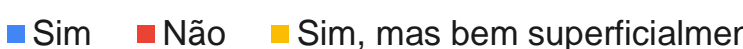

\section{LIÇÕES APRENDIDAS}

De acordo com os resultados do questionário aplicado aos participantes, a capacitação atingiu as expectativas e os objetivos de $100 \%$ do público e assim, pode-se afirmar que o evento proporcionou um efeito positivo para as empresas, agregando conhecimento aos seus membros. Além disso, a LABIM conseguiu melhorar o seu networking
Verificou-se, por meio de um questionário aplicado pelo Google Forms, que - baseando-se nas exposições dos autores supracitados os participantes da capacitação entravam, a princípio, no Nível 0 , no qual há falta de competência em uma área particular e após a capacitação saíram com o Nível 1, que refere-se ao entendimento dos princípios e aplicabilidades práticas iniciais. 0 método de ensino-aprendizagem aplicado foi a experimentação, mesclando entre experimentação show e ilustrativa, segundo as definições de Taha et al., (2016).

Figura 2: Resultado, obtido por meio de questionário, sobre as expectativas dos participantes.

\section{A capacitação atingiu suas expectativas e objetivos como público?}

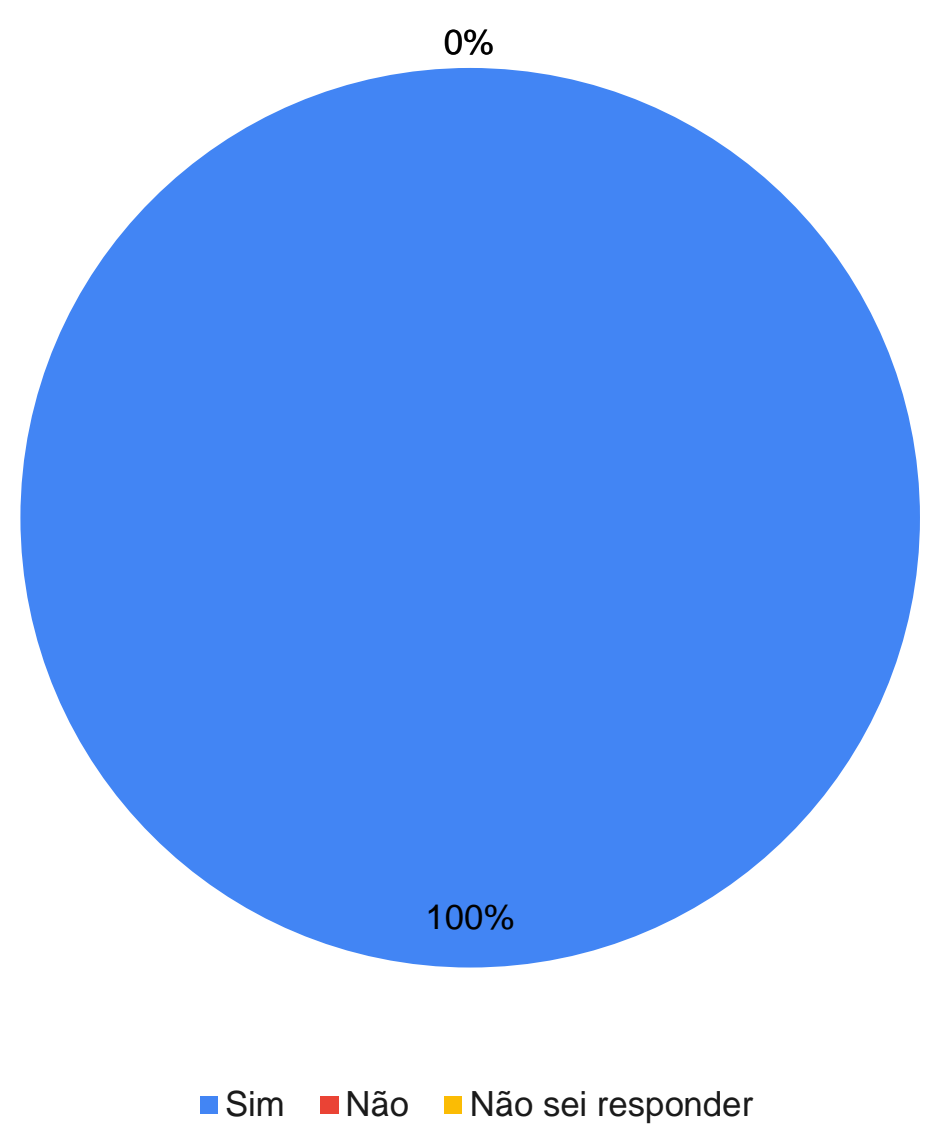

e divulgar ainda mais o seu trabalho.

Deste modo, com o evento realizado, a Liga conseguiu observar a eficácia dessa nova linha de atuação, que fora a capacitação de empresas. Como também, esse evento foi de muita importância para a ampliação dos conhecimentos de didática $\mathrm{e}$ comunicação dos membros da LABIM.
Ivna Feitosa Alencar 1

Joyce Fernandes Frutuôso 2

Joel Evangelista S. S. Leite 3

1-UFCA, ivna.feitosa@aluno.ufca.edu.br 2- UFCA, joyce.frutuoso@aluno.ufca.edu.br 3- UFCA, joelevangelista255@gmail.com

\section{INTRODUÇÃOO}

A capacitação foi oferecida pela LABIM (Liga Acadêmica de BIM) e ocorreu em ambiente virtual, em razão das restrições da pandemia da Covid-19. Ela foi direcionada para as empresas juniores Projetta e Pilares, da UFCA e da UEPB respectivamente, no âmbito do ensino do BIM. A experiência ocorreu do dia 20 ao dia 24 de julho de 2020. Essa formação complementar foi direcionada para os alunos de engenharia civil que faziam parte das empresas juniores citadas, onde foi apresentado um ensino sobre processos colaborativos dentro da tecnologia BIM. Com o intuito de obter um melhor desempenho nas suas atividades dentro dessas empresas.

\section{AGRADECIMENTOS}

À LABIM (Liga Acadêmica de BIM) que auxiliou na elaboração dos questionários e à Proex por incentivar as ações de extensão com BIM na universidade. 